\title{
Nghiên cứu giải thích quá trình hình thành ý định tự tử ở sinh viên
}

Nguyễn Thanh Nhàn (Trường ĐH Ngoại Thương) 08/07/2021 11:52

Mới đây, nhóm tác giả thuộc Trường ĐH Phenikaa đã công bố bài báo khoa học giải thích quá trình hình thành ý định tự tử ở sinh viên, từ đó đề xuất giải pháp ngăn chă̆n.

Nghiên cứu Alice in Suicideland: Exploring the Suicidal Ideation Mechanism through the Sense of Connectedness and Help-Seeking Behaviors Behaviors của nhóm tác giả thuộc trường Đại học Phenikaa được đăng trên tạp chí International Journal of Environmental Research and Public Health (JIF 2019 = 2.849; CiteScore 2019 = 3.0) chính là nghiên cứu đâuu tiên ứng dụng cơ chế xử lý thông tin Mindsponge để giải thích quá trình hình thành ý nghĩ tự sát [1].

Cùng với mô hình Mindsponge, nghiên cứu này sử dụng bộ dữ liệu về sức khỏe tinh thần của 286 sinh viên sinh viên Trường ĐH Ritsumeikan Asia Pacific University (APU) đến từ 86 quốc gia (75\% sinh viên quốc tế và $25 \%$ sinh viên Nhật Bản) để giải thích cảm giác kết nối ảnh hưởng đến ý tưởng tự sát như thế nào.
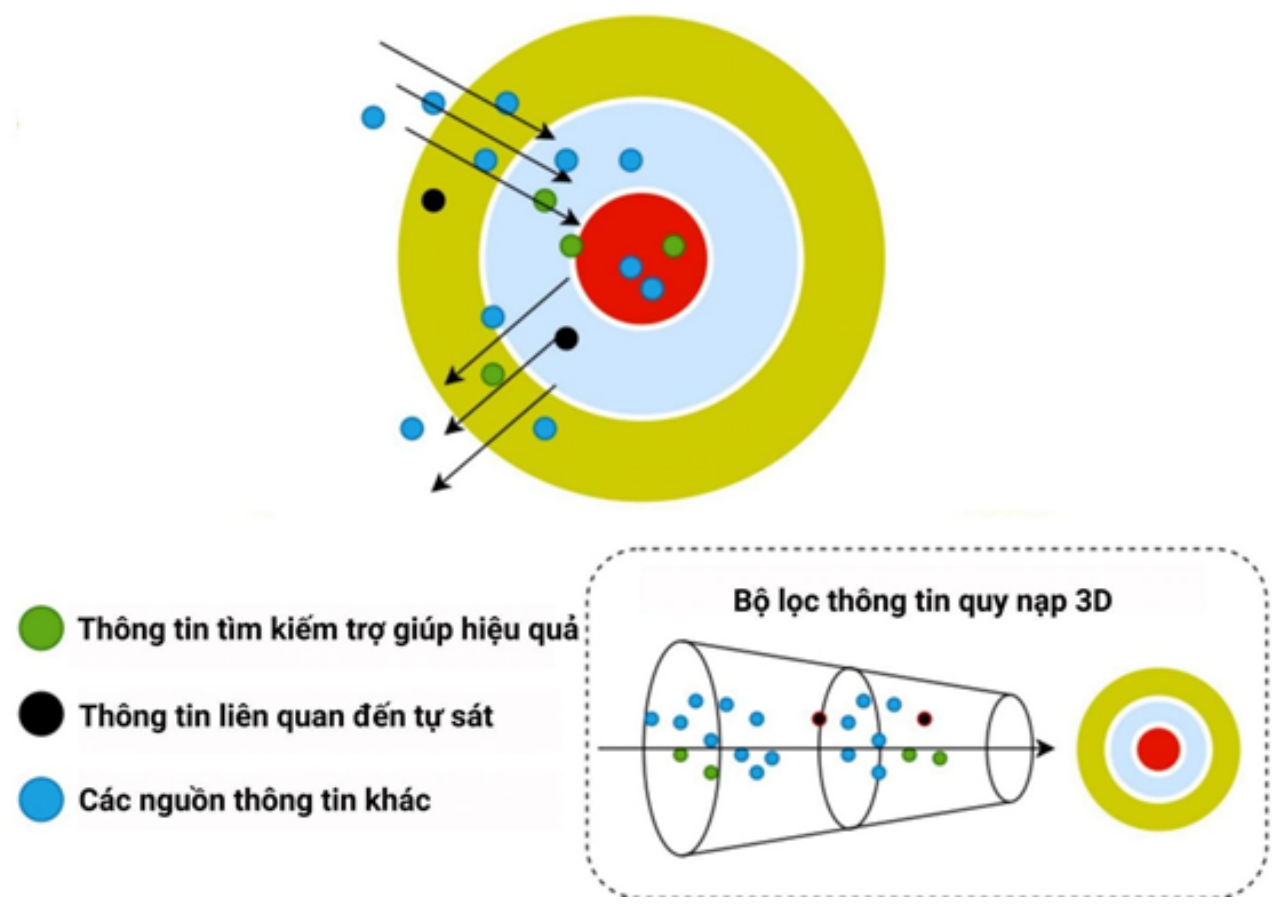
Hình 1. Cơ chế Mindsponge về quá trình hình thành ý định tự sát và tìm kiếm giúp đỡ. Nguồn:

Nguyen et al. (2021)

Hình 1 chính là cơ chế Mindsponge về quá trình hình thành ý định tự sát và tìm kiếm giúp đỡ. Vòng tròn màu đỏ thể hiện tư duy cốt Iõi của sinh viên, nơi lưu trữ những niềm tin và giá trị. Vòng tròn màu vàng bên ngoài thể hiện môi trường xã hội xung quanh sinh viên. Để đi vào bên trong thì thông tin cần phải qua bộ lọc 3D, thể hiện bằng vòng tròn màu xanh lam nhạt. Đây là vùng đệm đánh giá thông tin đi vào dựa trên lợi ích - chi phí mà thông tin đem lại.

Nhìn vào đây, đầu tiên ta thây thông tin từ môi trường xung quanh gồm thông tin tìm kiếm trợ giúp (từ người thân hoặc từ bác sĩ), thông tin liên quan đến tự sát (áp lực về tâm lý, trâm cảm, cô đơn, lo lắng) và các nguồn thông tin khác. Theo cơ chế Mindsponge, trước khi ý định tự sát đi sâu vào tư duy của mỗi người, họ sẽ lọc thông tin và cân nhắc sự được mất khi tự sát. Tuy nhiên, ngoài lựa chọn tự sát, họ cũng có rất nhiều lựa chọn khác như chia sẻ và tìm kiếm sự giúp đỡ từ bố mẹ, người thân trong gia đình hoặc nhờ tư vấn tâm lý từ các bác sĩ. Sau khi cân nhắc, sinh viên sẽ đưa ra quyết định và họ chọn tự sát nếu thấy rằng việc tự sát giúp họ giải thoát khỏi những đau khổ, túng quẫn trong cuộc sống. Khi đưa ra quyết định thì lựa chọn đó sẽ đi vào vòng tròn màu đỏ, tức là đi vào tư duy của người đó.

Theo nhóm tác giả tại Trường ĐH Phenikaa, để ngăn chặn ý định tự tử ở sinh viên thì cần phải có những yếu tố sau:

1) Các nguồn thông tin giúp đỡ hiệu quả - cần có những biện pháp tiếp cận kịp thời, cung cấp thông tin trợ giúp cho những sinh viên đang ở trong tình thế túng quẫn.

2) Nâng cao cảm giác kết nối với xã hội bằng cách xây dựng niềm tin - việc gia đình, thây cô hay bạn bè xây dựng niềm tin bằng cách quan tâm, chia sẻ và thấu hiểu sinh viên sẽ giúp sinh viên cảm thấy tin tưởng, từ đó dễ dàng kết nối với gia đình, bạn bè và tin tưởng thông tin trợ giúp do họ cung cấp.

3) Thay đổi các định kiến của xã hội (ít nhất là trong chính gia đình) về người có bệnh tâm lý thay vì dùng những ánh mắt kì thị đối với người có bệnh về tâm lý thì hãy quan tâm, thông cảm và động viên họ. Bởi vì bớt đi một ánh mắt kì thị, bớt đi một số lời bàn tán biết đâu có thể cứu được mạng sống của một con người.

Do đó, chúng ta cần đào sâu thêm vào vấn đề này và có những biện pháp kịp thời để không chỉ giúp sinh viên mà còn giúp những cộng đồng khác thoát khỏi sự tuyệt vọng khi lâm vào bước đường cùng.

Theo số liệu của một số nghiên cứu, tỷ lệ trẻ vị thành niên ở Việt Nam bị trầm cảm là 26,3\%; trẻ có suy nghĩ về cái chết là $6,3 \%$; trẻ lập kế hoạch tự tử và trẻ tìm cách tự tử lên đến hơn 11\% [2]. Trong đó, hầu hết số học sinh tự tử rơi vào độ tuổi 14 - 15, độ tuổi phải đối mặt với 
nhiều vấn đề, bất ổn về tâm lý [3].

Còn nhìn chung, tại Việt Nam, số người tự tử hằng năm lên tới gần 40.000 người, cao gấp 4 lần số ca tử vong do tai nạn giao thông [4]; trong khi hệ thống chăm sóc sức khỏe tinh thần vẫn còn lạc hậu, yếu kém. Nước ta hiện có 43 bệnh viện tâm thần, 100 cơ sở bảo trợ xã hội, trong đó có 27 cơ sở chăm sóc chuyên biệt cho người tâm thần (chỉ đáp ứng được 40\% nhu câu) [5]. Nếu như ở các nước phát triển việc đến bệnh viện hay các cơ sở y tế để chăm sóc sức khỏe tâm lý là chuyện bình thường thì tại các nước châu Á như Việt Nam đó lại là một điều "bất thường" do văn hóa kỳ thị và phân biệt đối xử đã có từ lâu.

\section{Tài liệu tham khảo:}

[1] Nguyen, M., Le, T., Nguyen, H. T., Ho, M., Huyen, N. T. T., \& Vuong, Q. (2021). Alice in Suicideland: Exploring the Suicidal Ideation Mechanism through the Sense of Connectedness and Help-Seeking Behaviors. International Journal of Environmental Research and Public Health, 18(7), 3681. https://doi.org/10.3390/ijerph18073681

[2] https://suckhoedoisong.vn/tu-tu-o-nguoi-tre-tuoi-dau-long-thoi-khong-du-n188707.html

[3] https://anninhthudo.vn/bao-dong-tinh-trang-ngay-cang-nhieu-gioi-tre-muon-sang-ngangthe-gioi-post373798.antd

https://nhandan.vn/tin-tuc-y-te/moi-nam-gan-40-nghin-nguoi-tu-tu-vi-benh-tramcam-289539/

[5] https://nhandan.com.vn/bhxh-va-cuoc-song/quan-tam-cham-soc-nguoi-benh-tamthan-643019/

\section{Nguyễn Thanh Nhàn (Trường ĐH Ngoại Thương)}

